\title{
Experimental and Numerical Dynamic Properties of Two Timber Footbridges Including Seasonal Effects
}

\author{
John Hallak Neilson ${ }^{1}$ - Aida Ibisevic ${ }^{1} \cdot$ Hasanhüseyin Ugur ${ }^{1}$. Jean-Marc Battini ${ }^{1} \cdot$ Roberto Crocetti $^{1} \cdot$ Costin Pacoste $^{2}$. \\ Maria D. Martinez-Rodrigo ${ }^{3}$
}

Received: 1 July 2020 / Revised: 11 January 2021 / Accepted: 27 March 2021 / Published online: 6 May 2021

(c) The Author(s) 2021

\begin{abstract}
This paper deals with experimental and numerical dynamic analyses of two timber footbridges. Both bridges have a span of $35 \mathrm{~m}$ and consist of a timber deck supported by two timber arches. The main purpose is to investigate if the dynamic properties of the bridges are season dependent. To this end, experimental tests are performed during a cold day in winter and a warm day in spring in Sweden. The first bending and transverse mode frequencies increase $22 \%$ and $44 \%$, respectively, due to temperature effects in the case of Vega Bridge. In the case of Hägernäs bridge, the corresponding values are 5\% and $26 \%$. For both bridges, the measured damping coefficients are similar in winter and spring. However, the damping coefficients for the first bending and transverse modes are different for both footbridges: about $1 \%$ for the Hägernäs bridge and $3 \%$ for the Vega bridge. Finite-element models are also implemented. Both numerical and experimental results show good correspondence. From the analyses performed, it is concluded that the connections between the different components of the bridges have a significant influence on the dynamic properties. In addition, the variation of the stiffness for the asphalt layer can explain the differences found in the natural frequencies between spring and winter. However, due to the uncertainties in the modelling of the asphalt layer, this conclusion must be taken with caution.
\end{abstract}

Keywords Pedestrian bridges $\cdot$ Dynamic analysis $\cdot$ Damping $\cdot$ Finite-element modelling $\cdot$ Dynamic testing

\section{Introduction}

Jean-Marc Battini

jean-marc.battini@byv.kth.se

John Hallak Neilson

jphneilson@gmail.com

Aida Ibisevic

aidaib@kth.se

Hasanhüseyin Ugur

hugur@kth.se

Roberto Crocetti

crocetti@kth.se

Costin Pacoste

costin.pacoste@elu.se

Maria D. Martinez-Rodrigo

mrodrigo@uji.es

1 Department of Civil and Architectural Engineering, KTH, Royal Institute of Technology, Stockholm, Sweden

2 ELU Konsult, Stockholm, Sweden

3 Department of Mechanical Engineering and Construction, Universitat Jaume I, Castellón, Spain
In addition to its ecological benefits, wood presents several advantages as construction material for pedestrian bridges: it provides a high-bearing capacity relative to the self-weight; it has the ability, by incorporating steel details, of satisfying the nowadays increasing aesthetic demand; it allows for an industrial manufacturing process in which large parts of the structure are produced and transported to site for easy erection and assembling, etc. In fact, very long-span pedestrian bridges may be designed [1]. However, the relatively low stiffness of timber bridges in combination with their low self-weight may result in uncomfortable vibrations for crossing pedestrians, and therefore, accurate dynamic analyses are often required in the design process. For this reason, the experimental and dynamic performances of timber bridges have been the purpose of several research works in the last decade [2-5], including structural health monitoring analyses [6], evaluation of natural frequencies variations with the time and use [7], etc. 
Whereas simple finite-element (FE) models can often be used for static analyses of wooden pedestrian bridges, for dynamic analyses more sophisticated models are often necessary. The main reason for this is that the connections between the different structural parts have a large influence on the stiffness of the structure when the bridge is subjected to small amplitudes of vibration and, consequently, these connections must be modelled carefully. In fact, several studies [8-10] have shown that predicting the stiffness of the connections in the design phase is very challenging and that it can only be done accurately after completion of the bridge by calibrating the model against experimental measurements.

Another difficulty for the dynamic analysis of wooden pedestrian bridges is related to the assessment of the additional stiffness attributable to the asphalt layer, associated to the asphalt material itself but also to the degree of composite action between the asphalt and the timber deck. These effects have been studied by several researchers through dynamic experiments both in laboratory $[11,12]$ and on existing bridges [12-14]. All these works show that the effect of the stiffness of the asphalt pavement on the natural frequencies depends on the temperature: it is not relevant in summer but it becomes important in winter. This is related to the viscoelastic temperature-dependent properties of the asphalt, but also to the shear action between the asphalt and the deck which is low in summer and high in winter. These works also point out that wooden pedestrian bridges with asphalt present higher damping ratios for the lowest natural frequency than bridges without asphalt [11]. However, no apparent correlation between ambient temperature and damping has been observed on existing bridges so far [12].

The purpose of this paper is to study, both experimental and numerically, the dynamic properties of two existing pedestrian wooden bridges. Both bridges present a span length of approximately $35 \mathrm{~m}$ and consist of a timber deck supported by two timber arches. Experimental tests are performed both in winter and in spring seasons to investigate the influence of the ambient temperature on the dynamic properties. Several FE models are implemented for each bridge. Two key aspects are the modelling of the connections and the material parameters for the asphalt layer. The two main objectives of this work are to investigate to what extent the natural frequencies and associated damping ratios for these two bridges are affected by temperature, and to develop accurate FE models able to reproduce the main dynamic properties of the structures.

\section{Vega Bridge}

\subsection{Description}

The Vega bridge (see Figs. 1 and 2) was built in March 2017 to enable crossing over the railway tracks of the commuter train in the municipality of Haninge, approximately $40 \mathrm{~km}$ south of Stockholm. The structure consists of a 3-hinged arch and it was prefabricated and hoised in place. The deck is a Stress Laminated Timber Deck (SLTD), made of a number of glulam beams (each with a $142 \times 315 \mathrm{~mm}^{2}$ cross-section) transversally prestressed by steel rods every $60 \mathrm{~cm}$. The deck presents a $2 \%$ transversal slope to facilitate water drainage and it is covered by an asphalt layer with a thickness of $85 \mathrm{~mm}$. The V-shaped disposition of the steel hangers is selected to increase the buckling capacity and the dynamic performance of the structure [15]. The deck is supported by four steel cross-beams. The two arches are connected through six K-shaped braces. Both the arch and the braces are made of glulam.

\subsection{Experimental Setup}

Experimental testing was performed during cold (March 11th, 2019: $-6{ }^{\circ} \mathrm{C}$ ) and warm (May 15th, 2019: $15{ }^{\circ} \mathrm{C}$ ) weather conditions. Eighteen accelerometers were installed. To design the experimental setup (Fig. 3), a preliminary FE model was developed. Thus, the positions of the accelerometers on the deck were chosen so that meaningful amplitudes occur for each mode and the excitation points were chosen at the maximum amplitude of each mode. An accelerometer (not shown in Fig. 3) was also attached to the lowest transverse brace to capture the lateral vibration of the arch. The bridge was excited using two methods: an impact hammer and a free falling from an $80 \mathrm{~kg}$ person from a height of $30 \mathrm{~cm}$. The results were then post-processed applying a low-pass Butterworth filter with a cutoff frequency of $20 \mathrm{~Hz}$ and a Fast Fourier Transformation to identify the natural frequencies and eigenmodes. The damping coefficients were obtained using the half power bandwidth method. To get a high degree of confidence in the results, the experimental damping coefficients have been determined using many records (from several accelerometers and tests). The

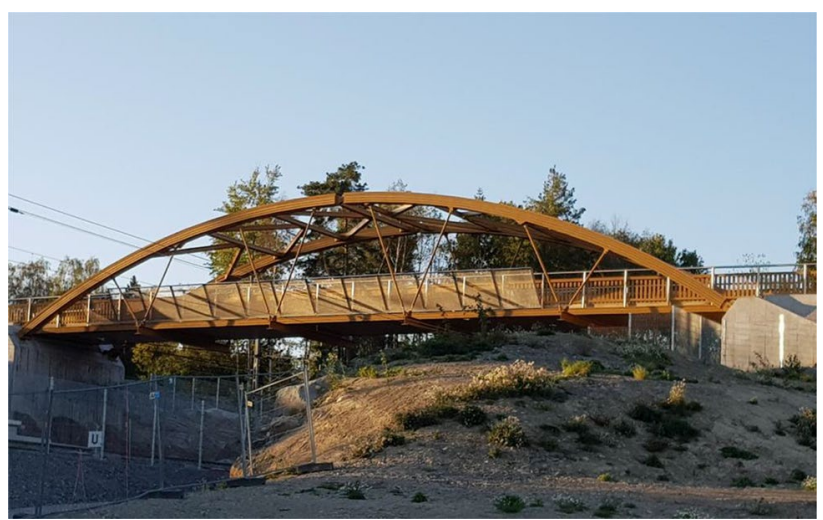

Fig. 1 Vega bridge 


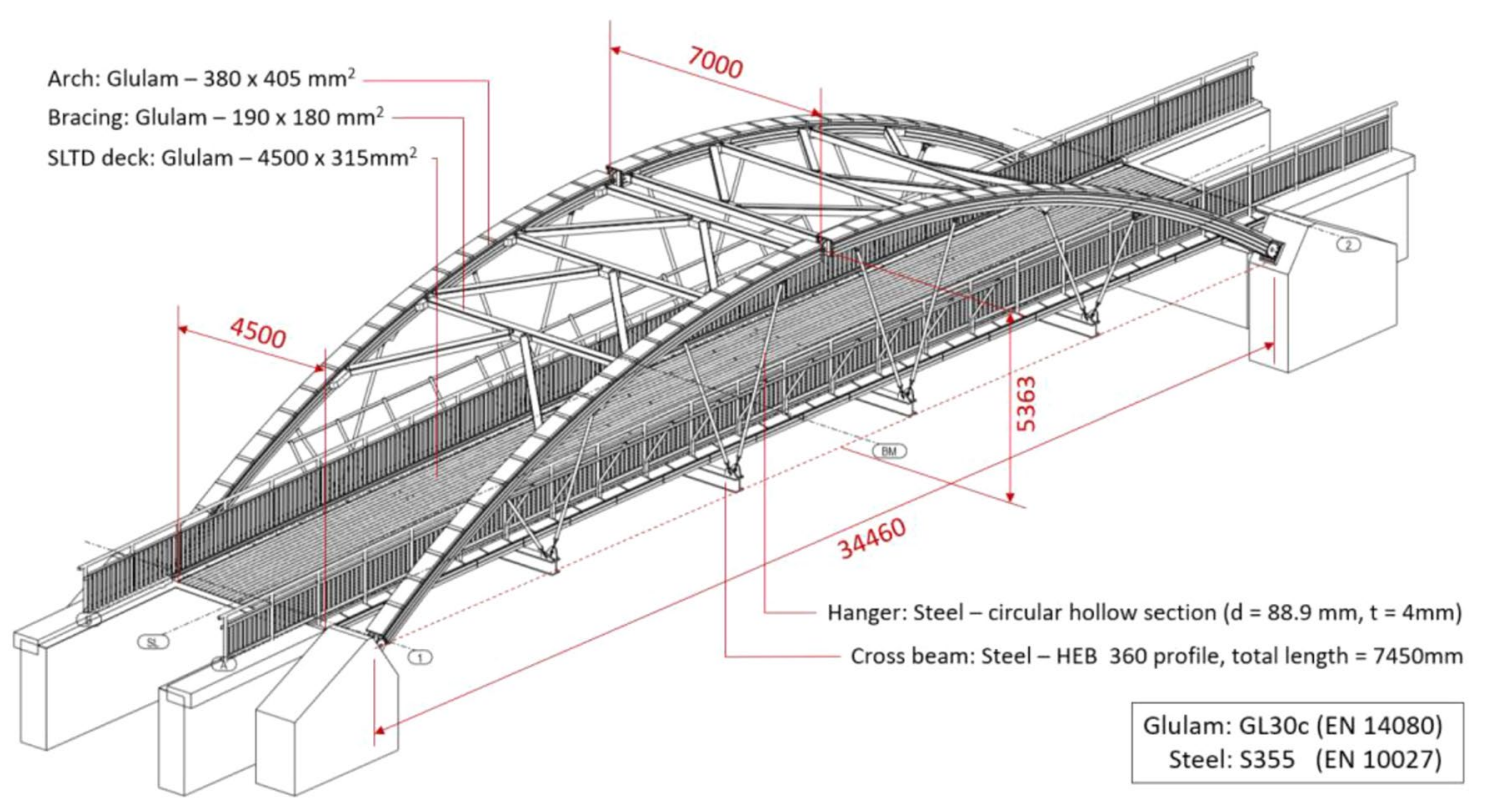

Fig. 2 Vega bridge: dimensions, materials and cross-section

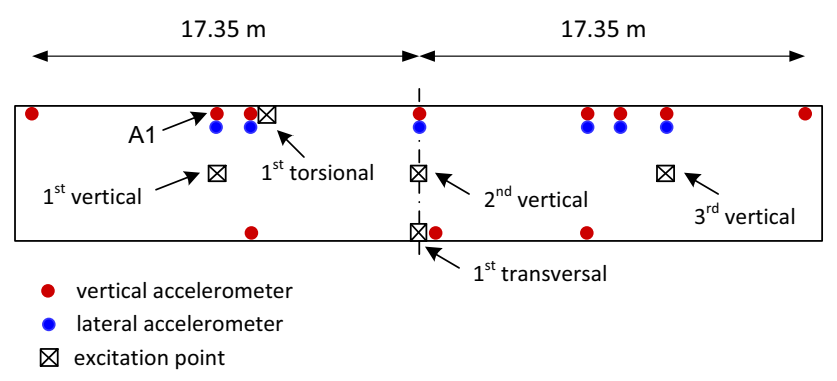

Fig. 3 Vega bridge: experimental setup

obtained values are presented in term of average value and standard deviation Fig. 4.

\subsection{Finite-Element model}

Three models were implemented in Abaqus. They differ in the way the asphalt layer is considered. The models consist of the following parts: arch, braces, hangers, cross-beams, deck and for Models 2 and 3, the asphalt layer.

The arch and the bracings were modelled using 2 node shear flexible 3D beam elements. The dimensions of the rectangular cross-sections are given in Fig. 2. The isotropic Modulus of Elasticity, Poisson's ratio and mass density of the Glulam material were taken as $E=13 \mathrm{GPa}$, $\nu=0.2$ and $\rho=440 \mathrm{~kg} / \mathrm{m}^{3}$, respectively. The hangers and the cross-beams (see Fig. 2) were also modelled using 2 node shear flexible 3D beam elements. The material parameters for steel were taken as $E=210 \mathrm{GPa}, \nu=0.3$ and $\rho=7850 \mathrm{~kg} / \mathrm{m}^{3}$. The SLTD deck consists of timber

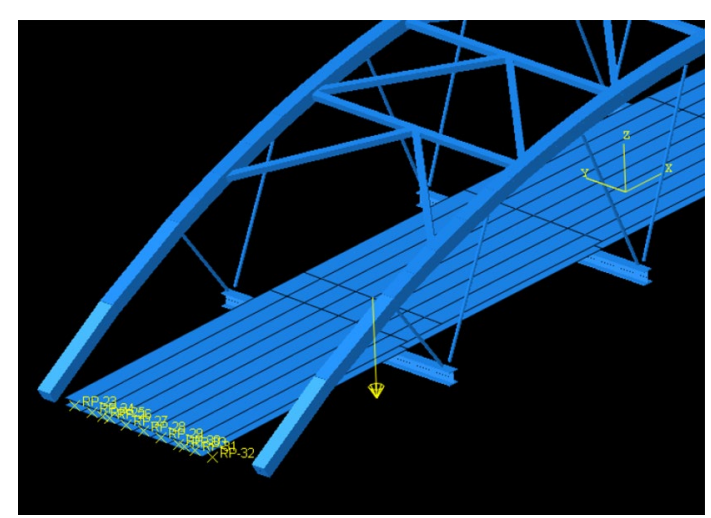

Fig. 4 Vega bridge: FE model

beams of height $0.315 \mathrm{~m}$ prestressed transversally, thus, carrying load mainly through friction. It was modelled using 4 node orthotropic shell elements with $E_{\mathrm{x}}=13 \mathrm{GPa}$, $E_{\mathrm{y}}=0.26 \mathrm{GPa}, G_{\mathrm{xy}}=G_{\mathrm{xz}}=0.78 \mathrm{GPa}, G_{\mathrm{yz}}=0.078 \mathrm{GPa}$. All these material properties, and also the ones for the second bridge, were provided by the manufacturers.

The asphalt layer presents a height of $85 \mathrm{~mm}$. In Model 1 , the stiffness of the asphalt layer was neglected and the mass of the asphalt was directly added to the mass of the deck. In Models 2 and 3, the asphalt layer stiffness contribution was considered using isotropic 4 node shell elements with $\nu=0.3$ and $\rho=2243 \mathrm{~kg} / \mathrm{m}^{3}$ connected to the deck. Two values for the asphalt Elastic Modulus were considered: $3 \mathrm{GPa}$ (a realistic value under warm conditions) for Model 2 and $25 \mathrm{GPa}$ (a realistic value under cold conditions) for Model 3. 


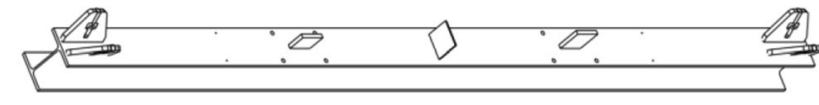

Fig. 5 Vega bridge: cross-beam

A hinge at the crown of the arch was introduced by allowing only the rotation around the transversal axis. The interactions arch/bracing, arch/hanger and hanger/cross-beams were simulated using tie constraints that permit rotations, and by introducing offsets so that the connections are located at the exact positions. However, additional numerical tests show that if these offsets are removed or if the tie constraints are also applied to the rotations, the change in the relevant natural frequencies is less than $1 \%$.

The connection between the cross-beams and the deck must be modelled in an accurate way since it has a significant influence on the dynamic behavior of the bridge. As shown in Fig. 5, this connection is materialized with steel plates that are welded to the cross-beams and inserted in the timber deck. Hence, for each of the steel beams, coupling constraints are defined at three points, with vertical and transversal translational restraints for the central section and vertical and longitudinal translational restraints for the other two sections. It can be observed that if full interaction (using tie constraints over the entire length) between the deck and the cross-beams is considered, the vertical and torsional natural frequencies are overestimated by as much as $25 \%$.

The interaction between the asphalt layer and the timber deck in Models 2 and 3 depends on the degree of composite action between both materials. To establish an upper bound to the influence of the stiffness of the asphalt, a full shear connection is assumed using offsets corresponding to half of the thickness for both the deck and the asphalt, and using tie constraints between both the surfaces.

Two sets of boundary conditions are introduced: at the arch springings and at the deck abutments. The arches ends are inserted on a concrete block through a steel device (see Fig. 6) that, ideally, only allows for rotation around the $y$ axis. However, in the next section, it will be shown that this steel device does not completely restrain rotations around the $x$ and $z$ axes, and that rotational springs around $x$ and $z$ axes are necessary to match the experimental results.

The deck is supported continuously along the abutments length. The restraints of the horizontal translations are forced by steel plates (see DET 1 in Fig. 7), which are embedded in the concrete at the abutment in one end and inserted into the deck at the other. The outermost plates are oriented in a way to prevent longitudinal displacement, whereas the one at the centre prevents transversal displacement. These boundary conditions are introduced in the deck by defining reference points with an offset of half of the deck height.
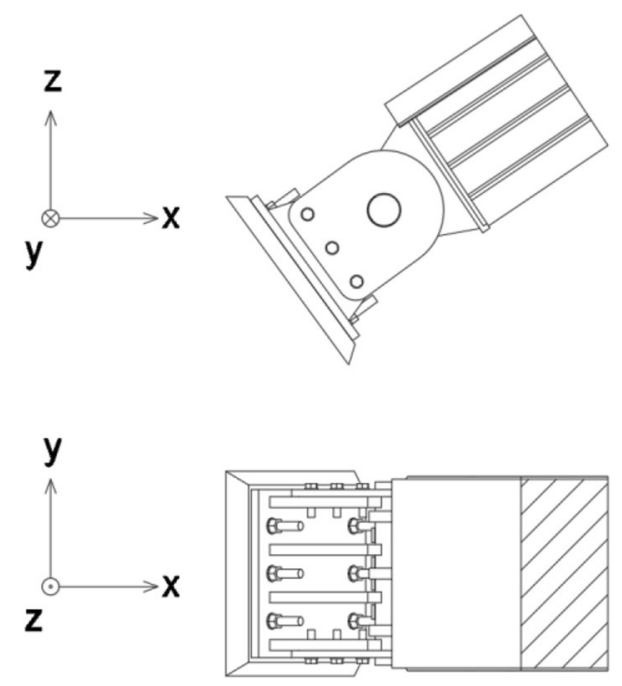

Fig. 6 Vega bridge: arch boundary device

Vertical translations are restrained along the width of the deck and longitudinal or transverse translations, depending on the orientation of the plate, are restrained at the location of the steel plates. Longitudinal restraints are present at only one abutment. It can be noted that introducing the same boundary conditions eliminating the offsets would decrease the natural frequency for the first transverse mode by $17 \%$.

\subsection{Experimental and Numerical Results}

The experimental and numerical natural frequencies are presented in Table 1. The ratios between experimental frequencies under cold and warm conditions are shown in parentheses together with experimental frequencies in cold conditions. For each model, the ratios between numerical and experimental results are included in parenthesis as well. Identified experimental damping ratios are presented in Table 2. The numerical mode shapes are shown in Fig. 8. It can be observed that the experimental mode shapes, not shown in figures, are very close to the numerical ones. The frequency representation of the signals for accelerometer A1 (see the position in Fig. 3) recorded after two hammer tests are shown in Fig. 9. It can be observed that the lowest modes are well identified both under warm and cold conditions.

The experimental results show clearly that the temperature has a significant influence on the natural frequencies, and that a decrease leads to an increase of the stiffness. Compared to warm conditions, the natural frequencies in cold conditions are $44 \%$ higher for the first transversal mode and $22 \%$ higher for the first vertical bending mode. The high impact of the temperature change for the first transverse mode compared to the bending and torsional modes was expected since the change in the stiffness of the asphalt with the temperature affects especially this mode. 


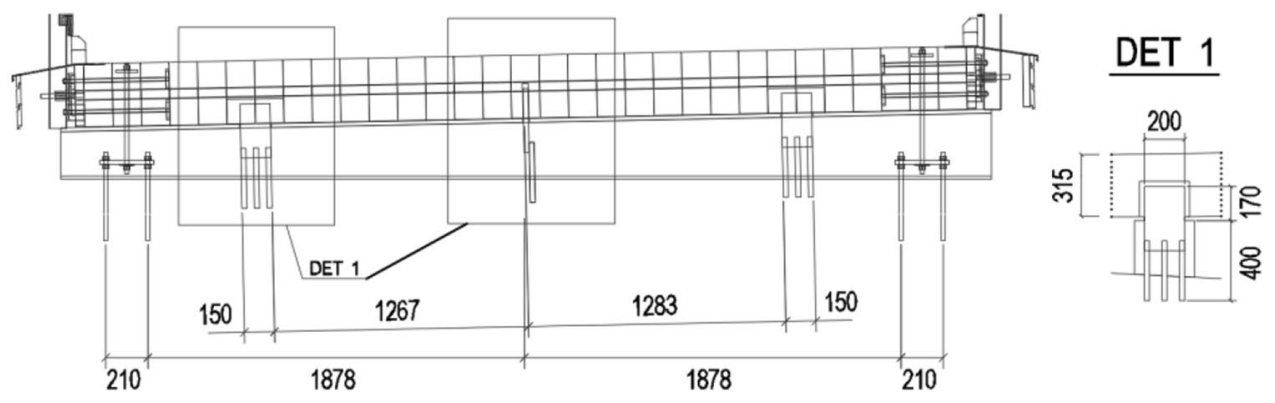

Fig. 7 Vega bridge: deck support device

Table 1 Vega bridge: experimental and numerical natural frequencies [Hz]

\begin{tabular}{|c|c|c|c|c|c|}
\hline Vibration mode & $\begin{array}{l}\text { Exp. freq. (warm: } \\
15^{\circ} \mathrm{C} \text { ) }\end{array}$ & $\begin{array}{l}\text { Exp. freq. (cold: - } \\
\left.6{ }^{\circ} \mathrm{C}\right)\end{array}$ & Model 1 (warm) & Model 2 (warm) & Model 3 (cold) \\
\hline 1st transverse mode (arch) & 2.43 & $2.54(1.04)$ & $3.18(1.31)$ & $2.48(1.02)$ & $2.48(0.98)$ \\
\hline 1 st vertical mode & 2.88 & $3.50(1.21)$ & $2.68(1.07)$ & $2.80(0.97)$ & $3.27(0.93)$ \\
\hline 2nd vertical mode & 3.51 & $3.86(1.10)$ & $3.54(1.01)$ & $3.69(1.05)$ & $4.03(1.04)$ \\
\hline 3rd vertical mode & 5.13 & $6.27(1.22)$ & $4.95(0.96)$ & $5.26(1.02)$ & $6.17(0.98)$ \\
\hline 1st transversal mode & 4.53 & $6.53(1.44)$ & $4.16(0.92)$ & $4.62(1.02)$ & $6.41(0.98)$ \\
\hline 1st torsional mode & 4.57 & $5.44(1.19)$ & $5.35(1.17)$ & $5.68(1.24)$ & $6.43(1.18)$ \\
\hline
\end{tabular}

Table 2 Vega bridge: experimental damping ratios

\begin{tabular}{|c|c|c|}
\hline Vibration mode & $\begin{array}{l}\text { Damping ratio } \\
\text { (cold: }-6{ }^{\circ} \mathrm{C} \text { ) }\end{array}$ & Damping ratio (warm: $15^{\circ} \mathrm{C}$ ) \\
\hline 1st vertical mode & $3.4 \pm 0.3$ & $\begin{array}{l}\text { Hammer: } 1.7 \pm 0.4 \\
\text { Free fall: } 3.2 \pm 0.1\end{array}$ \\
\hline 2nd vertical mode & $3.1 \pm 0.2$ & $1.5 \pm 0.30$ \\
\hline 3rd vertical mode & $3.0 \pm 0.7$ & $\begin{array}{l}\text { Hammer: } 0.9 \pm 0.3 \\
\text { Free fall: } 2.8 \pm 0.4\end{array}$ \\
\hline 1st transversal mode & $4.5 \pm 0.2$ & $4.0 \pm 0.7$ \\
\hline 1st torsional mode & $2.0 \pm 0.6$ & $2.4 \pm 0.4$ \\
\hline
\end{tabular}

A clear variation in the damping ratios due to the temperature cannot be clearly identified even though the values tend to be lower under warm conditions, with exception of the first torsional mode for which the damping ratio is slightly higher in spring and the second bending mode for which the damping ratio is much lower in spring. For this bridge, with a high number of connections and different components, it is difficult to identify the sources of damping and, consequently, to explain some of the differences in the experimental results. Besides, it can be observed that the values of damping were almost all higher than the one suggested by Eurocode (1.5\% for structures with mechanical joints). Different results were obtained for the first and third bending modes in warm conditions with the hammer and the free falling tests. One explanation for this could be that the damping for these modes depends on the amplitude of the vibrations which are higher for the free falling test when compared to the hammer test. This effect, i.e. amplitude-dependent damping, has also been observed in railway bridges in $[16,17]$.

A good agreement between the natural frequencies obtained with Model 1 and the experimental ones can be observed, with the exception of the first transversal mode of the arch and the first torsional mode. In Model one, the stiffness of the asphalt is neglected, which can be a realistic assumption with warm temperature. To obtain more accurate numerical results and based on the fact that the first transversal mode of the arch has virtually no contribution from the deck (see Fig. 10) or from temperature change, the following modifications were performed in Models 2 and 3: rotational springs around $x$ and $z$ axes were applied at the arch springings and their stiffnesses were chosen so that the natural transversal frequency for the arch was the average of the experimental results. This change did not affect the vertical mode shapes, as expected, but it did reduce the frequency for the torsional mode.

The results from Model 2, in which the asphalt layer is modelled with an elastic modulus of 3 GPA, are in very good agreement with the experimental ones (warm temperature), except for the torsional mode. The results obtained with Model 3, in which the asphalt layer is modelled with an elastic modulus of 25 GPA, are also in good agreement with the experimental results (cold temperature), except for the torsional mode. In fact, the differences for the natural 


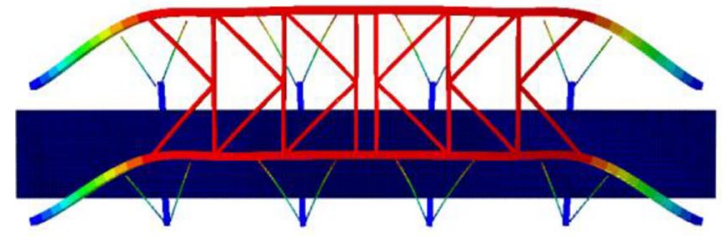

(a) $1^{\text {st }}$ transversal mode $(\operatorname{arch}) f=3.18 \mathrm{~Hz}$

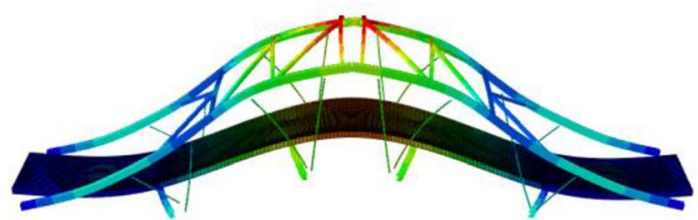

(c) $2^{\text {nd }}$ vertical mode (deck) $f=3.54 \mathrm{~Hz}$

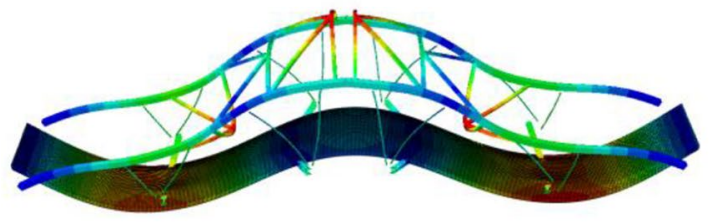

(e) $3^{\text {rd }}$ vertical mode (deck) $f=4.95 \mathrm{~Hz}$

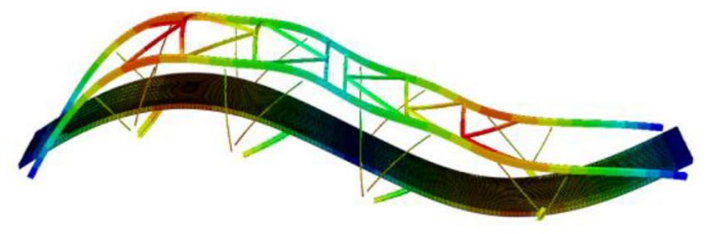

(b) $1^{\text {st }}$ vertical mode (deck) $f=2.68 \mathrm{~Hz}$

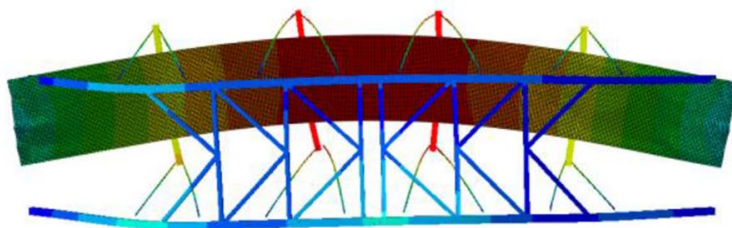

(d) $1^{\text {st }}$ transversal mode (deck) $\mathrm{f}=4.16 \mathrm{~Hz}$

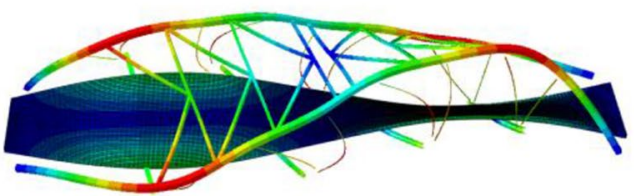

(f) $1^{\text {st }}$ torsional mode (deck) $f=5.35 \mathrm{~Hz}$

Fig. 8 Vega bridge: numerical mode shapes

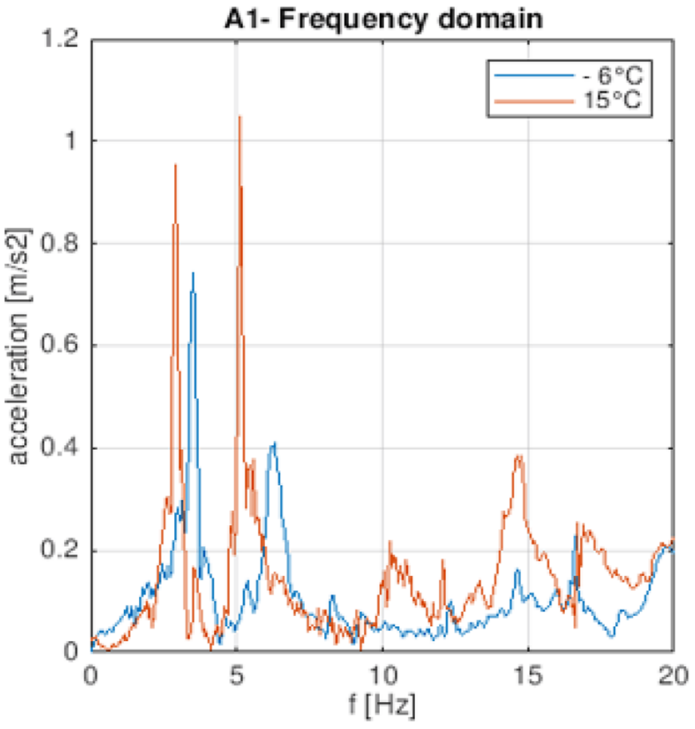

Excitation point: $1^{\text {st }}$ vertical

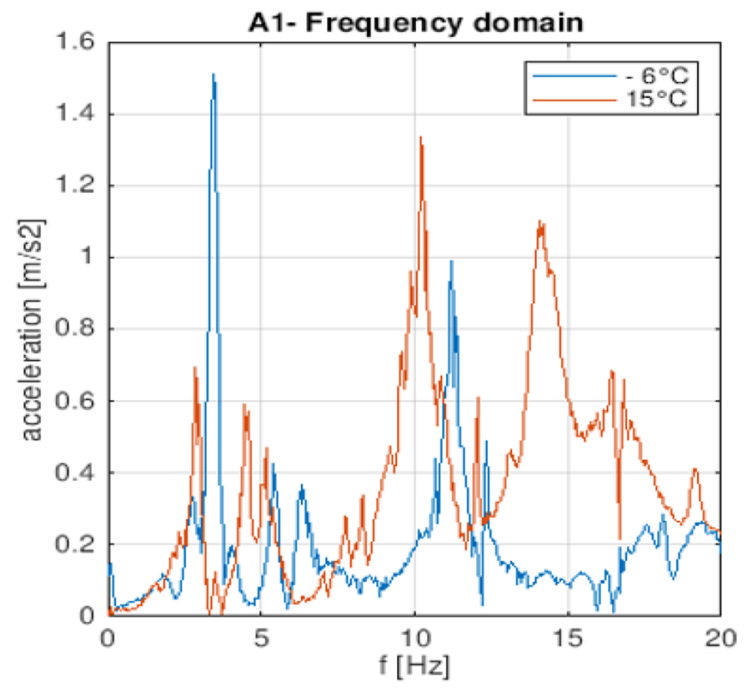

Excitation point: $1^{\text {st }}$ torsional

Fig. 9 Vega bridge: frequency responses of accelerometer A1 for the hammer tests 

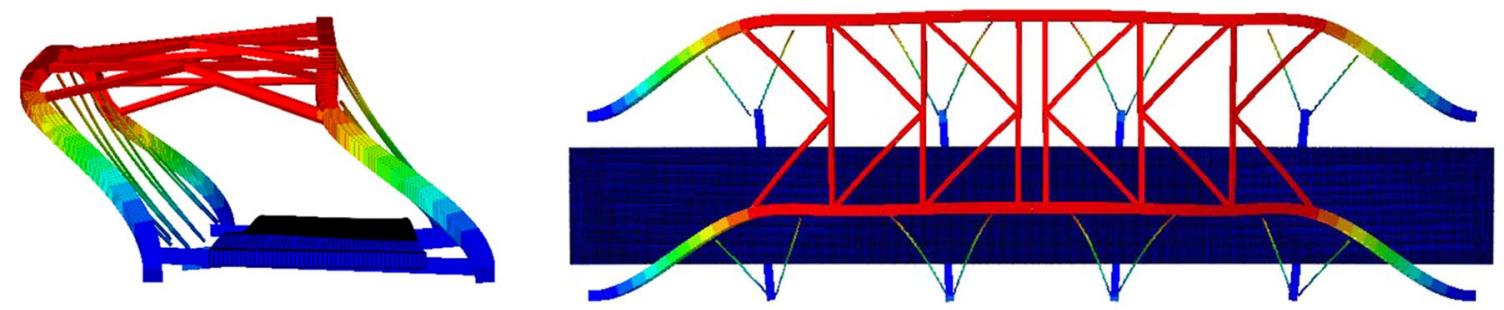

Fig. 10 Vega bridge: transverse mode (arch)

frequencies between Models 3 and 2 are 39\% for the first transverse mode and $17 \%$ for the first vertical mode, which are close to the experimental values (44\% and $18 \%$ ) given above. Therefore, it seems that the differences in the experimental frequencies between warm and cold conditions can be explained to a large extent by the effect of the asphalt. However, this conclusion must be taken with caution since both the adopted values for the asphalt stiffness and the adopted full shear connection between the deck and asphalt layers can be debated.

\section{Hägernäs Bridge}

\subsection{Description}

Located in Täby, north of Stockholm, the Hägernäs bridge, see Figs. 11, 12 and Table 3, was built in 2007 to enable crossing over the highway E18. The 42-m-long bridge horizontal structure, which leans on a 3-hinged arch, is a composite structure consisting of five longitudinal beams made of glulam and a deck of cross-glued laminated veneer lumber (LVL, type Q) which is screw-glued on the top of the glulam beams. The LVL deck consists of two LVL plates, each $63 \mathrm{~mm}$ thick, which are glued together. Thirteen lateral glulam beams, each of them consisting of 6 short parts, are placed between the longitudinal beams. The longitudinal beams rest on concrete abutments at the ends as well as on four steel beams. Two of the steel beams are attached to the glued laminated timber arches. The other two steel beams are attached to steel hangers, forming two stiff U-frames, which in turn are attached to the arches. The two arches are laterally stabilized through two cross-braces placed between the springings of the arches and the steel beams. The deck is covered by an asphalt layer with a thickness of $75 \mathrm{~mm}$.

\subsection{Experimental Setup}

Experimental testing was performed during cold (March 5th, 2019: $-10^{\circ} \mathrm{C}$ ) and warm (May 17th, 2019: $17^{\circ} \mathrm{C}$ ) weathers. 15 accelerometers were installed in March and 18 in May (see Figs. 13 and 14). Just as in the Vega bridge case, the experimental setup in March was planned on the basis of a preliminary FE analysis. The setup was then slightly modified in May, mainly to get a better representation of the flexural mode shapes. It can also be noted that the lateral accelerometers, on the left hand side of the first transversal excitation point and on both sides of the bridge for the setup in March, were not placed on the deck like all the other ones but on the vertical hangers. The same two sources of excitation as well as the same post-processing procedure of the raw data as in the previous case were applied.

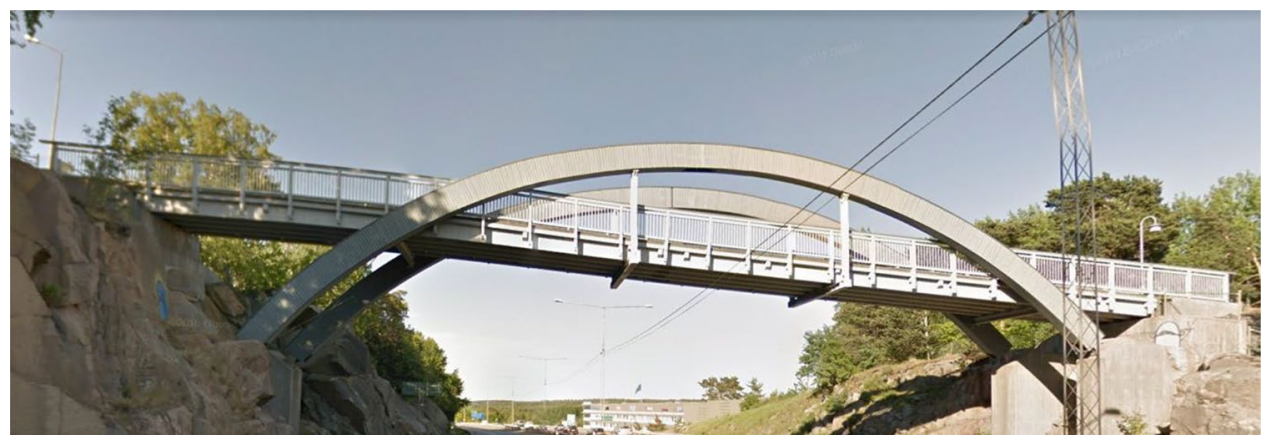

Fig. 11 Hägernäs bridge 


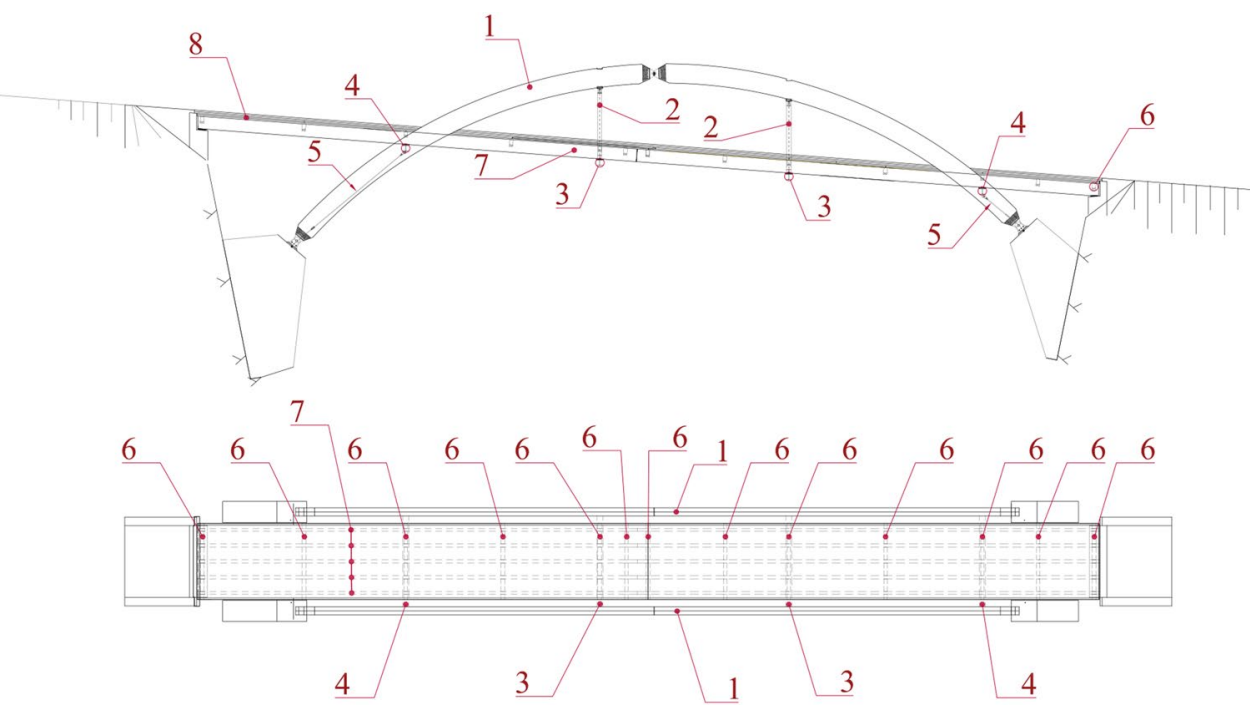

Fig. 12 Hägernäs bridge: structural components

Table 3 Hägernäs bridge: structural components, materials and dimensions

\begin{tabular}{lllll}
\hline Numbering in Fig. 11 & Description & Material & Classification & Cross-section \\
\hline 1 & Arch & GLT & GL30c (L40) & $380 \times 900$ \\
2 & Hanger & Steel & S355 & HEA200 \\
3,4 & Steel beam & Steel & S355 & HEA280 \\
5 & Cross-bracing & Steel & S355 & M30 \\
6 & Trans. beam & GLT & GL30c (L40) & $165 \times 315$ \\
7 & Longit. Beam & GLT & GL30c (L40) & $140 \times 585$ \\
8 & Deck & LVL & Kerto-Q & $3530 \times 63$ \\
\hline
\end{tabular}

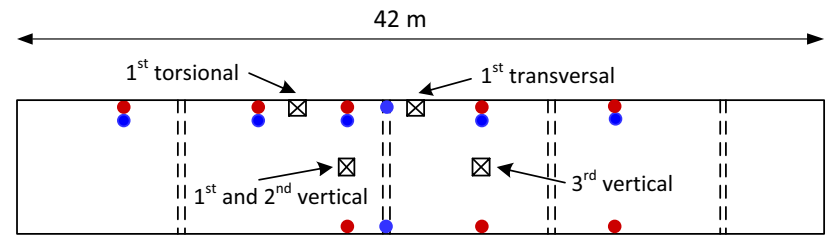

- vertical accelerometer

- lateral accelerometer

$凶$ excitation point

Fig. 13 Hägernäs bridge: experimental setup in March

\subsection{Finite-Element Model}

Four models are implemented in Abaqus, see Fig. 15. The deck was modelled using 4 node orthotropic shell elements with a thickness of $126 \mathrm{~mm}$. The material parameters are $E_{\mathrm{x}}=10.5 \mathrm{GPa}, E_{\mathrm{y}}=2.4 \mathrm{GPa}, G_{\mathrm{xy}}=0.6 \mathrm{GPa}, G_{\mathrm{xz}}=0.12 \mathrm{GPa}$, $G_{\mathrm{yz}}=0.22 \mathrm{GPa}$ and $\rho=550 \mathrm{~kg} / \mathrm{m}^{3}$.

The arches as well as the 5 longitudinal and 13 transversal beams were modelled using 2 node shear flexible 3D

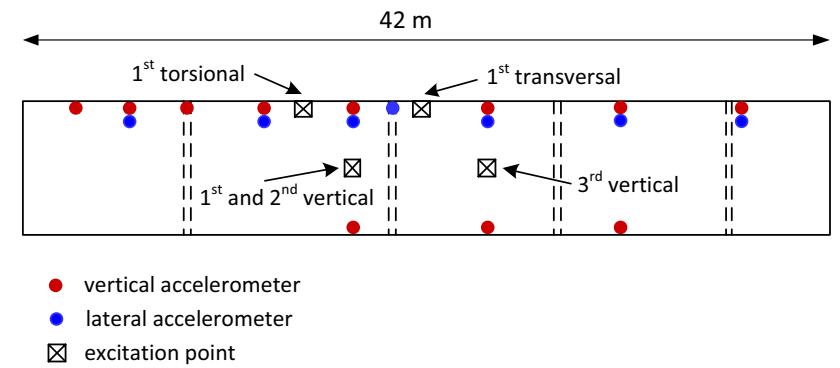

Fig. 14 Hägernäs bridge: experimental setup in May

beam elements. To avoid overlapping between the longitudinal and transversal beams, rigid links corresponding to half of the width of the longitudinal beams were introduced when defining the transversal beams. The isotropic material parameters for the arches and the GLT beams were taken as $E=10.4 \mathrm{GPa}, \nu=0.2$ and $\rho=440 \mathrm{~kg} / \mathrm{m}^{3}$. The steel beams and the hangers were also modelled with 2 node shear flexible 3D beam elements, whereas the crossbraces were modelled using 2 node 3D truss elements. The 


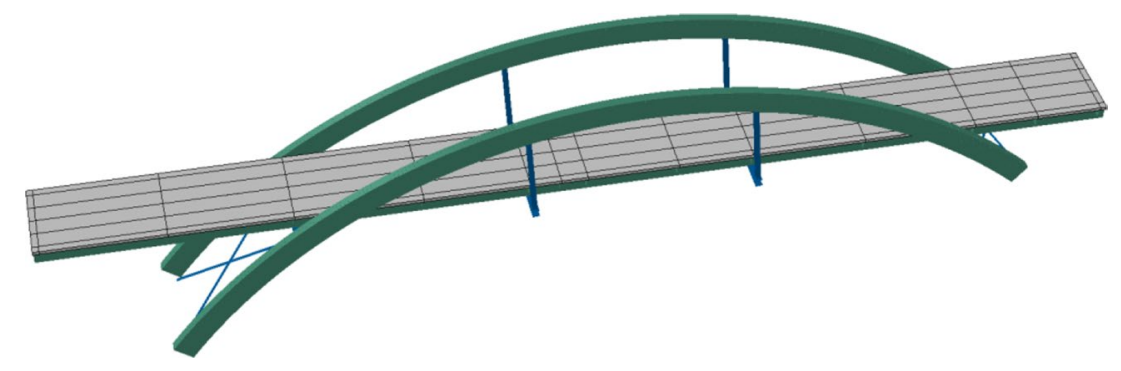

Fig. 15 Hägernäs bridge: FE model

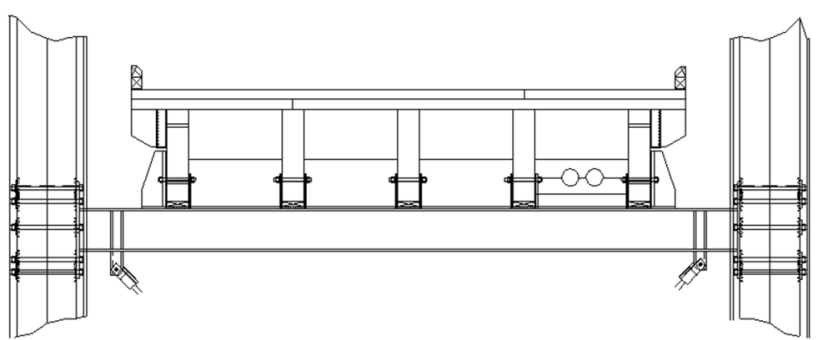

Fig. 16 Hägernäs bridge: connection steel beam/long beam

material parameters for steel were taken as $E=210 \mathrm{GPa}$, $\nu=0.3$ and $\rho=7850 \mathrm{~kg} / \mathrm{m}^{3}$.

The asphalt layer presents a thickness of $75 \mathrm{~mm}$. In Models 1 and 2, the stiffness of the asphalt layer is neglected and the mass of the asphalt is just added to the mass of the deck. In Models 3 and 4, the asphalt layer is included in the same way as for the Vega bridge, with identical material parameters.

The connections between the structural parts are simulated consistently for small amplitudes of vibration. A hinge at the crown of the arch is introduced by allowing only the rotation around the transversal axis. The interactions steel beam/hanger, steel beam/arch, longitudinal beam/transverse beam and longitudinal beam/deck are represented using tie constraints for both displacements and rotations. The bolted connection between the hangers and the arches allows certain rotation in two directions, around the vertical and transversal axes. To model this particular behavior, a rigid body constraint with two connectors is used.

The longitudinal timber beams, see Fig. 16, rest on the steel beams and are placed between two steel plates welded to the top of the steel beams. The steel plates have slotted holes to accommodate the difference in thermal expansion between steel and timber. The two beams are connected with steel rods connected to the elongated holes. These connections allow small rotations around the three axes and also vertical translation to a certain extent. Each connection is modelled using a rigid body constraint between the midsurface of both beams and the two connectors. In Model 1, the connector situated at the horizontal beam prevents all the translations and rotations whereas the connector situated at the steel beam prevents only the three translations. In Models 2, 3 and 4, the vertical translation between both beams is taken into account by introducing a vertical spring at the connector at the steel beam.

The bridge rests on concrete foundations and the following boundary conditions are considered. All the translations at the two ends of the cross-braces are restrained. The arches are connected with hinges that allow only the rotation around the transversal axis at the supports. At the abutments, for each longitudinal beam two steel plates with holes are cast into the concrete. The beam is placed between the plates and screwed to it. At one of the abutments, the holes in the steel plates allow no movements whereas at the other abutment the holes permit longitudinal displacement. In the model, reference points with an offset of half the deck height are created at both ends of all the longitudinal beams. At one end, only the rotation around the transversal axis is allowed whereas at the opposite end, the rotation around the transversal axis and the longitudinal translation are allowed.

\subsection{Experimental and Numerical Results}

The experimental and numerical natural frequencies are presented in Table 4. The ratios between experimental frequencies under cold and warm conditions are shown in parentheses together with experimental frequencies under cold conditions. For each model, the ratios between numerical and experimental results are shown in parentheses. The experimental damping ratios are presented in Table 5. The numerical mode shapes are shown in Fig. 17. It can be observed that the experimental mode shapes, not shown in the figures, are very close to the numerical ones.

The experimental results show that the temperature has a significant influence on the natural frequency for the first transversal mode (the difference between cold and warm conditions is $26 \%$ ) but not for the vertical and torsional modes (the difference between cold and warm condition is 5-7\%). As for the Vega bridge, a higher impact of the temperature change for the first transverse mode compared to 
Table 4 Hägernäs bridge: experimental and numerical natural frequencies [Hz]

\begin{tabular}{lllllll}
\hline Vibration mode & $\begin{array}{l}\text { Exp. freq. } \\
\left(\text { warm: } 17^{\circ} \mathrm{C}\right)\end{array}$ & $\begin{array}{l}\text { Exp. freq. (cold: } \\
\left.-10^{\circ} \mathrm{C}\right)\end{array}$ & Model 1 (warm) & Model 2 (warm) & Model 3 (warm) & Model 4 (cold) \\
\hline 1st vertical mode & 5.13 & $5.37(1.05)$ & $5.70(1.11)$ & $5.36(1.04)$ & $5.46(1.06)$ & $5.66(1.05)$ \\
2nd vertical mode & 5.71 & $6.14(1.07)$ & $6.28(1.10)$ & $5.68(0.99)$ & $5.79(1.01)$ & $6.08(0.99)$ \\
3rd vertical mode & 6.18 & $6.56(1.06)$ & $7.12(1.15)$ & $6.94(1.12)$ & $6.97(1.13)$ & $7.11(1.08)$ \\
1st transversal mode & 4.36 & $5.50(1.26)$ & $4.87(1.12)$ & $4.79(1.10)$ & $5.13(1.18)$ & $6.04(1.10)$ \\
1st torsional mode & 6.71 & $7.18(1.07)$ & $7.43(1.11)$ & $7.13(1.06)$ & $7.28(1.08)$ & $7.59(1.06)$ \\
\hline
\end{tabular}

Table 5 Hägernäs bridge: experimental damping ratios

\begin{tabular}{lll}
\hline Vibration mode & $\begin{array}{l}\text { Damping ratio } \\
\left(\text { cold: }-10^{\circ} \mathrm{C}\right)\end{array}$ & $\begin{array}{l}\text { Damping ratio } \\
\left(\text { warm: } 17^{\circ} \mathrm{C}\right)\end{array}$ \\
\hline 1st vertical mode & $1.0 \pm 0.3$ & $1.0 \pm 0.1$ \\
2nd vertical mode & $1.2 \pm 0.3$ & $1.2 \pm 0.4$ \\
3rd vertical mode & $1.4 \pm 0.4$ & $1.1 \pm 0.2$ \\
1st transversal mode & $0.8 \pm 0.1$ & $2.0 \pm 0.2$ \\
1st torsional mode & $1.0 \pm 0.2$ & $1.2 \pm 0.2$ \\
\hline
\end{tabular}

the bending and torsional modes was expected, since the change in the stiffness of the asphalt with temperature affects especially this mode. Except for the first transversal mode, no differences regarding the damping coefficients were observed between warm and cold conditions. It can also be noted that almost all the identified damping values were slightly lower than the one suggested by Eurocode (1.5\% for structures with mechanical joints).

The natural frequencies obtained with Model 1, in which the stiffness of the asphalt is neglected and without springs between the longitudinal timber beams and the steel beams, are higher than the experimental ones in warm conditions. Hence, in Model 2, vertical springs with a stiffness of 10 $\mathrm{MN} / \mathrm{m}$ are introduced between the longitudinal and the steel beams which improved the correlation with experimental results. It can also be noted that with a stiffness of 100 $\mathrm{MN} / \mathrm{m}$ for the springs, the same results are obtained with

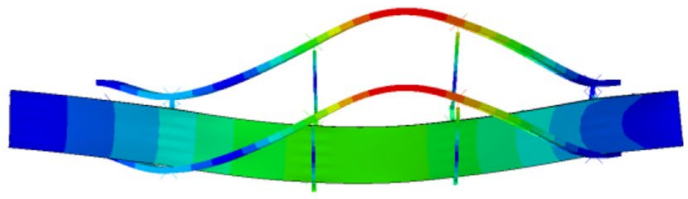

(a) $1^{\text {st }}$ transversal mode $f=4.79 \mathrm{~Hz}$
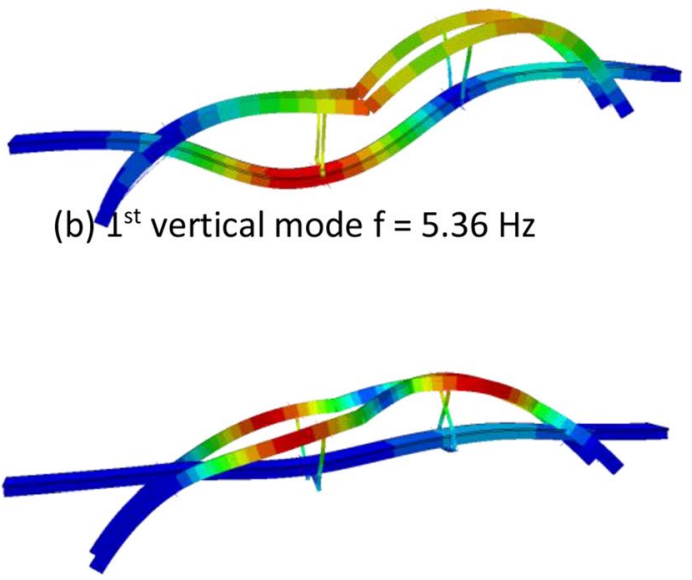

(d) $3^{\text {rd }}$ vertical mode $f=6.94 \mathrm{~Hz}$

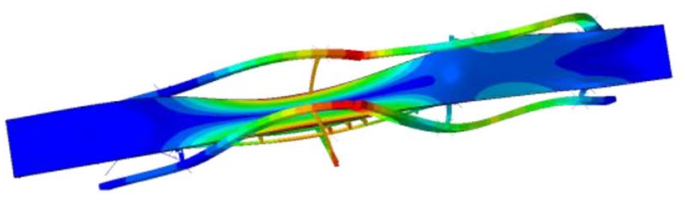

(e) $1^{\text {st }}$ torsional mode $f=7.13 \mathrm{~Hz}$

Fig. 17 Hägernäs bridge: numerical mode shapes 
Models 1 and 2. In Model 3, the asphalt layer is explicitly introduced with an elastic modulus of $3 \mathrm{GPa}$ and almost the same results as with Model 2 are obtained, with the exception of the transverse mode for which the asphalt layer has a larger influence. In Model 4, the elastic modulus of the asphalt is increased up to $25 \mathrm{GPa}$ to represent cold conditions. The differences for the natural frequencies between Models 3 and 4 are 18\% for the first transverse mode and $4 \%$ for the first vertical mode, which is close to the experimental values (26\% and 5\%) given above. Therefore, and as for the Vega bridge, it seems that the differences in the experimental frequencies between warm and cold conditions can be justified by the stiffness of the asphalt to a large extent. However, as for the Vega bridge, this conclusion must be taken with caution.

\section{Conclusions}

In this paper, experimental and numerical analyses of two timber pedestrian bridges are presented. Both bridges have a span of approximately $35 \mathrm{~m}$ and consist of a timber deck supported by two timber arches. Experimental tests are performed under warm and cold conditions. The experimental results show that temperature has a significant influence on the natural frequencies of the bridges, especially for the first transversal mode, and that a decrease of the temperature leads to an increase of the stiffness. For the Vega bridge, the natural frequencies in cold conditions are $44 \%$ higher for the first transversal mode and $22 \%$ higher for the first vertical one compared to warm conditions. For the Hägernäs bridge, the corresponding values are $26 \%$ and $6 \%$.

For both bridges, the measured damping coefficients are similar in winter and spring. However, and compared to the values suggested by Eurocode (1.5\%), higher damping coefficients are identified for the Vega bridge (between $2 \%$ and $4.5 \%$ ) and slightly lower ones for the Hägernäs bridge (about $1 \%$ ).

Several FE models are implemented for each bridge. These models show that the connections between the different components of the bridge must be considered carefully to obtain accurate results compared to the experimental natural frequencies. In fact, for several connections, different modelling alternatives are tested to see their impact on the natural frequencies. In some of the models, an asphalt layer, composed by shell elements, are introduced above the deck and tied to it. Two different moduli of elasticity ( $3 \mathrm{GPa}$ and $25 \mathrm{GPa}$ ) are used for the asphalt for warm and cold conditions, respectively. The numerical results tend to show that the differences in the experimental frequencies between warm and cold conditions can be attributed to the stiffness of the asphalt to a large extent. However, this conclusion must be taken with caution since both the adopted values for the asphalt stiffness and the adopted full shear connection between the deck and asphalt layers are debatable.

It is difficult to derive general conclusions from only two case studies and additional studies are necessary to explain why the changes in the natural frequencies between warm and cold conditions are more important for the Vega bridge. But it can be concluded that seasonal variations should be considered for assessing timber footbridges bridges against vibrations. If experimental studies have to be performed for this assessment, then it is better to do them in warm conditions when the natural frequencies are lower and the bridge is, therefore, more sensitive to pedestrian vibrations. Additional experimental studies are also necessary to explain the differences in the identified damping levels between these two bridges.

Funding Open access funding provided by Royal Institute of Technology.

Open Access This article is licensed under a Creative Commons Attribution 4.0 International License, which permits use, sharing, adaptation, distribution and reproduction in any medium or format, as long as you give appropriate credit to the original author(s) and the source, provide a link to the Creative Commons licence, and indicate if changes were made. The images or other third party material in this article are included in the article's Creative Commons licence, unless indicated otherwise in a credit line to the material. If material is not included in the article's Creative Commons licence and your intended use is not permitted by statutory regulation or exceeds the permitted use, you will need to obtain permission directly from the copyright holder. To view a copy of this licence, visit http://creativecommons.org/licenses/by/4.0/.

\section{References}

1. Zhou M, Zhuang H, An L (2019) A long span wooden arch bridge with glued laminated timber. StrucEngInt 10(1080/10168664):1679061

2. Altunışık AC, Kalkan E, Okur FY, Karahasan O, Ozgan K (2020) Finite element model updating and dynamic responses of reconstructed historical timber bridges using ambient vibration test results. J Perform ConstrFacil 34(1):04019085

3. Toyoda A, Honda H, Kato S (2020) Static and dynamic structural performance of modern timber bridges. J Japan Soc Civil Eng $8(1): 26-34$

4. Castro-Triguero R, Garcia-Macias E, Flores ES, Friswell MI, Gallego R (2017) Multi-scale model updating of a timber footbridge using experimental vibration data. EngComput 34(3):754-780

5. Fiore A, Liuzzi MA, Greco R (2020) Some shape, durability and structural strategies at the conceptual design stage to improve the service life of a timber bridge for pedestrians. ApplSci 10(6):2023

6. Palma P, Steiger R (2020) Structural health monitoring of timber structures - Review of available methods and case studies. Constr Build Mater 248:118528

7. Stiros S, Moschas F (2014) Rapid decay of a timber footbridge and changes in its modal frequencies derived from multiannual lateral deflection measurements. J BridgEng 19(12):05014005

8. Cecháková V, Rosmanit M, Fojtik R (2012) FEM modeling and experimental tests of timber bridge structure. Procedia Eng 40:79-84 
9. Cruz PJS, Salgado R, Branco J (2009) Dynamic analysis and structural evaluation of gois footbridge. MecânicaExperim 17:129-137

10. Rønnquist A, Wollebaek L, Bell K (2006) Dynamic behavior and analysis of a slender timber footbridge. 9th World Conference on Timber Eng WCTE 1:863-870

11. Schubert S, Gsell D, Steiger R, Feltrin G (2010) Influence of asphalt pavement on damping ratio and resonance frequencies of timber bridges. EngStruct 32:3122-3129

12. Feltrin G, Schubert S, Steiger R (2011) Temperature effects on the natural frequencies and modal damping of timber footbridges with asphalt pavement. In: 4th international conference on experimental vibration analysis for civil engineering structures (EVACES '11), Varenna, Italy

13. Hamm P (2007) Ein beitrag zum schwingungs- und dämpfungsverhalten von fussgängerbrücken aus holz. 2007, Report, Civil
Engineering, TU München, Fakultät für Bauingenieur- und Vermessungswesen, Germany

14. Gülzow A, Steiger R, Gsell D, Wilson W, Feltrin G (2007) Dynamic field performance of a wooden trough bridge. In: 2nd international conference on experimental vibration analysis for civil engineering structures (EVACES '07), Porto, Portugal

15. Crocetti R, Branco JM, Barros JF (2019) Timber arch bridges with V-shaped hangers. StructEngInt 29(2):261-267

16. Gonzalez I, Karoumi R (2014) Analysis of the annual variations in the dynamic behavior of a ballasted railway bridge using Hilbert transform. EngStruct 60:126-132

17. Rebelo C, Simões da Silva L, Rigueiro C, Pircher M (2008) Dynamic behaviour of twin single-span ballasted railway viaducts Field measurements and modal identification. EngStruct 30:2460-2469 